\title{
REVEGETAÇÃO DE ÁREAS DE MINERAÇÃO: CRITÉRIOS DE MONITORAMENTO E AVALIAÇÃO DO DESEMPENHO ${ }^{1}$
}

\author{
Raquel Olímpia Peláez Ocampo Almeida² e Luis Enrique Sánchez ${ }^{3}$
}

\begin{abstract}
RESUMO - A recuperação de áreas degradadas pela mineração normalmente envolve atividades que têm o objetivo de restabelecer a vegetação. O acompanhamento dos resultados dessa atividade é muitas vezes inexistente ou conduzido de maneira assistemática. $O$ trabalho seleciona um conjunto de indicadores com a finalidade de facilitar a tarefa de avaliação dos resultados da recuperação ambiental em áreas de extração de areia. O emprego de indicadores adequados facilita a compreensão e a interpretação dos resultados da revegetação para diferentes categorias de interessados, como empresários, agentes públicos e a comunidade em geral. Cinco indicadores selecionados - aspecto visual, densidade de plantas, altura média de plantas, número de espécies arbóreas e mortalidade de mudas - foram levantados em duas minas. Na primeira, foram avaliadas duas áreas revegetadas em uma bacia de disposição de rejeitos; na segunda mina, foi avaliada uma área de mata ciliar em vias de recuperação. Em parcelas situadas em cada mina foram medidos ou observados os parâmetros correspondentes aos indicadores selecionados. Os resultados apontam que as áreas ainda não atingiram o patamar esperado em termos de sucesso da revegetação. Os indicadores utilizados revelam-se eficazes para a avaliação pretendida, uma vez que podem ser obtidos com procedimentos de baixo custo, demandam pouco tempo, não requerem conhecimento especializado e representam satisfatoriamente o estado da área revegetada.
\end{abstract}

Palavras-chave: Revegetação, reabilitação de áreas degradadas, indicadores ambientais, mineração e areia.

\section{MONITORING AND EVALUATING PERFORMANCE OF MINING REVEGETATION}

\begin{abstract}
Rehabilitation of mined areas usually involves some revegetation. However, as follow-up is seldom implemented, the success of such programs is largely unknown. This paper reviews a set of indicators potentially applicable to monitoring and evaluating the results of revegetation in mined areas. A benefit of using indicators is that, ideally, they can facilitate the understanding and interpretation of obtained data, being useful to all stakeholders - mining company staff and managers, government agents, and community representatives.

The selected indicators: visual aspect, plant density, average plant height, number of tree species and seedlings mortality rate, were tested in two sand mined areas. The first features a revegetated tailings pond; the second area presents reestablished riparian vegetation.

Results show that the areas still did not reach the desired rehabilitation stage. Indicators were shown to be useful and effective for this evaluation; they can be quickly obtained at a low cost, do not demand specialized knowledge and satisfactorily represent the state of the areas.
\end{abstract}

Key words: Revegetation, rehabilitation, mined areas reclamation, performance indicators, sand mining

\footnotetext{
${ }^{1}$ Recebido em 07.11.2003 e aceito para publicação em 25.11.2004.

${ }^{2}$ Programa de Pós-Graduação em Engenharia Mineral - Escola Politécnica da USP.

${ }^{3}$ Departamento de Engenharia de Minas e de Petróleo - Escola Politécnica da USP.
} 


\section{INTRODUÇÃO}

A areia é uma matéria-prima essencial à sociedade, pelo seu uso em grande escala na construção civil e na indústria, o que se reflete no grande volume de produção. Segundo dados compilados pelo DNPM (2002), há no Brasil cerca de 2.000 empresas dedicadas à mineração de areia, que produziram cerca de 236 milhões de toneladas em 2001. No Estado de São Paulo, a areia é extraída principalmente nas várzeas aluvionares, desencadeando processos de degradação do meio físico, em especial do solo. No Brasil, a partir de 1989 todas as empresas de mineração são obrigadas a apresentar ao órgão ambiental um Plano de Recuperação de Áreas Degradadas (PRAD), documento que preconiza a adoção de procedimentos para estabelecer ou restabelecer a cobertura vegetal nas áreas degradadas, prática conhecida como revegetação.

No entanto, na implementação das medidas propostas nos PRADs é freqüente a ocorrência de dificuldades relativas ao manejo do solo e das plantas, que chegam a comprometer o sucesso da revegetação. Embora a exigência legal de recuperar áreas degradadas pela mineração já vigore há vários anos, subsistem dificuldades de ordem técnica, gerencial e econômica para levar a cabo adequadamente as tarefas de recuperação. Os procedimentos descritos nos PRADs muitas vezes não são seguidos na prática; em outros casos, seus resultados ficam aquém do esperado (BITAR, 1997). Existem ainda empresas que almejam implantar projetos efetivos de recuperação ambiental, mas faltalhes o conhecimento técnico para realizá-los com eficiência, especialmente no que se refere aos procedimentos de revegetação.

O acompanhamento, a físcalização e a avaliação dos resultados da implantação de medidas de recuperação ambiental em minerações de areia são raramente implementados de modo sistemático. As razões para a pouca importância atribuída à etapa de acompanhamento dos projetos são múltiplas (DIAS e SÁNCHEZ, 2001). Uma delas é a dificuldade de se estabelecerem parâmetros ou critérios para avaliação do desempenho das empresas ao executarem a recuperação de áreas degradadas.

Na mineração de areia, deve-se mencionar a Resolução SMA 42/96, da Secretaria do Meio Ambiente do Estado de São Paulo, que disciplinou a atividade extrativa de areia no vale do rio Paraíba do Sul.
Essa resolução determina aos mineradores a obrigação de seguirem uma série de procedimentos operacionais, com o objetivo de mitigar os impactos, e também estabelece medidas específicas para a recuperação das áreas degradadas. A resolução também estabelece valores de referência para certos parâmetros (altura média de planta, grau de cobertura e densidade de plantas, entre outros), com o intuito de avaliar o desempenho da revegetação. Várias empresas da região seguiram tais procedimentos, e resultados efetivos já são observados no que se refere ao restabelecimento da vegetação nativa. Santo e Sánchez (2002) constataram, através de monitoramento por fotografias aéreas de um trecho de 3.100 ha da várzea do rio Paraíba do Sul, no município de Jacareí, uma ampliação de 37 ha de área recuperada entre 1988 e 1998 , em face dos 48,5 ha suprimidos para fins de expansão das atividades minerárias.

Nas minerações de areia, em geral há dois tipos de áreas, onde é necessária a revegetação: (i) áreas de mata ciliar que, segundo o Código Florestal, são áreas de preservação permanente (APP) e devem ser revegetadas exclusivamente com espécies nativas; (ii) áreas operacionais da mineração, incluindo margens de cavas, áreas de disposição de rejeitos, locais de estocagem de areia, instalações de beneficiamento, oficinas, escritórios e demais construções, cuja revegetação pode, muitas vezes, ser feita com outras espécies e depende da reabilitação planejada e dos objetivos de uso da área após o encerramento da mineração. Na revegetação de APPs degradadas, tem sido usualmente recomendada a aplicação do modelo sucessional, que separa as espécies vegetais em grupos ecológicos com características comuns e funções diferentes na dinâmica da floresta (WEST et al., 1981; SWAINE e WITHMORE, 1988). O plantio, neste caso, deve ter o máximo possível de diversidade de espécies nativas, procurando-se recuperar tanto a estrutura quanto a dinâmica da floresta (RODRIGUES e GANDOLFI, 1998). A Resolução SMA 21/01 estipula que no mínimo devem ser plantadas 30 espécies diferentes por hectare.

O sucesso de um programa de revegetação pode ser avaliado segundo diferentes pontos de vista. $\mathrm{O}$ aspecto geral da vegetação, o porte dos indivíduos arbóreos, a diversidade do sub-bosque etc. podem ser critérios de fácil julgamento aos olhos do especialista ou do profissional experiente, mas são pouco úteis para fins de gestão ambiental. 
Essa avaliação pode ser feita mediante o uso de indicadores de desempenho. Para isso, devem ser recolhidos parâmetros que forneçam uma informação agregada e sintética sobre algum aspecto da própria vegetação ou do solo. Através deles, pode-se verificar a eficiência da cobertura vegetal na proteção dos solos, a produtividade dos ecossistemas ou mesmo sua função como refúgio da vida silvestre. Idealmente, os indicadores de desempenho deveriam ser objetivos, facilmente mensuráveis, reprodutíveis e passíveis de serem obtidos a baixo custo. Uma das vantagens do uso de indicadores é que possibilita fácil compreensão e interpretação dos dados por parte de diferentes categorias de interessados, como empresários, agentes públicos e comunidade em geral.

Há inúmeros parâmetros que podem ser utilizados como indicadores, mas o grande desafio é desenvolver ou adaptar critérios válidos para monitorar e avaliar a funcionalidade da área, bem como discriminar os indicadores que forneçam as informações desejadas com exatidão e a custos aceitáveis. Há que se buscar também outros indicadores específicos para cada situação e cada ambiente a ser recuperado, sendo improvável que se possam desenvolver apenas indicadores de uso universal (RODRIGUES e GANDOLFI, 2001).

Nas minerações de areia, a escolha de indicadores deve considerar os objetivos da recuperação ambiental. Via de regra, o objetivo prioritário da revegetação é alcançar a estabilidade física do local, para tanto pode-se avaliar a perda de solo da área em determinado tempo, por exemplo, mas propósitos específicos quanto ao uso futuro da área podem estar associados. Se o objetivo for o restabelecimento de vegetação nativa, a avaliação deverá contar, necessariamente, com dados de diversidade de espécies. Um reflorestamento precisará de dados de produção de biomassa ou densidade de plantas, e assim por diante.

O presente trabalho teve como objetivo testar a aplicabilidade do uso de indicadores para avaliar os resultados de programas de revegetação na mineração de areia, conduzindo um estudo-piloto em duas minas localizadas no Estado de São Paulo.

\section{MATERIAL E MÉTODOS}

\subsection{Características das áreas estudadas}

Duas minerações foram escolhidas por apresentarem dois tipos característicos de procedimentos de revegetação em lavra de areia: áreas de bacias de decantação de rejeitos (finos do processo de beneficiamento da areia) e áreas operacionais antigas, onde havia previamente matas ciliares.

A primeira mina está situada no município de São Paulo, SP, pertence à empresa Viterbo Machado Luz e lavra areia, contida em saprólito granítico, pelo método de desmonte hidráulico. A área avaliada tem 4 ha, com duas idades de plantio: cinco e nove anos, ambas implantadas em bacias de decantação desativadas. $\mathrm{Na}$ revegetação com cinco anos, o plantio de mudas (30 $\mathrm{cm}$ ) de espécies nativas arbóreas foi realizado em covas com espaçamento de $3 \times 3 \mathrm{~m}$. A preparação da superfície incluiu reposição de uma camada de 10 a $20 \mathrm{~cm}$ de solo argiloso, e as covas de $80 \mathrm{~cm}$ de diâmetro e $2 \mathrm{~m}$ de profundidade foram preenchidas com solo orgânico e $50 \mathrm{~g}$ de adubo. A manutenção realizada até o presente compreende o coroamento e corte do mato com máquina duas vezes ao ano, uso de formicida granulado e adubação dirigida nas covas. Na revegetação mais antiga não houve plantio de espécies arbóreas e sim semeadura a lanço de uma mistura de $8 \mathrm{~kg} / \mathrm{ha}$ de sementes de braquiária (Brachiaria decumbens) e $14 \mathrm{~kg} / \mathrm{ha}$ de capim-gordura (Melinis minutiflora). Para a preparação da superfície, realizou-se a disposição de uma mistura de solo orgânico e argiloso, numa camada de $0,5 \mathrm{~m}$. Não houve nenhuma atividade de manutenção posterior.

O segundo caso é o da Mineração Cinco Lagos, situada no município de Taubaté, SP. A areia é extraída de cavas abertas na várzea do rio Paraíba do Sul, usando-se dragas de sucção. Aárea revegetada escolhida para avaliação tem 4,5 ha e margeia o rio Paraíba; na sua parte central, apresenta um remanescente florestal de 1,8 ha. O plantio em leiras foi realizado há sete anos com mudas de arbóreas nativas $(30 \mathrm{~cm})$, seguindo dois tipos de espaçamentos: a área $\mathrm{A}$, com espaçamento de $6 \mathrm{~m}$ entre leiras e $1 \mathrm{~m}$ entre plantas; e a área B, com o espaçamento de 3,5 m entre leiras e 2,5 m entre plantas. A preparação do solo incluiu a reposição de uma primeira camada de $1 \mathrm{~m}$ de solo argiloso e, a seguir, a reposição de outra camada de 30 a 40 $\mathrm{cm}$ de solo orgânico. Durante os três primeiros anos foi possível realizar trato mecanizado para fertilização e controle da vegetação herbácea na área A. Já na área B o controle foi químico, devido ao fato de o espaçamento menor entre leiras não permitir o passo de máquinas.

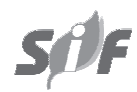

R. Árvore, Viçosa-MG, v.29, n.1, p.47-54, 2005 
O tipo de manejo do solo, os métodos de revegetação e as espécies utilizadas foram diferentes nas duas minerações. Contudo, não há registro do número de espécies utilizadas em nenhum dos casos.

\subsection{Obtenção de dados}

Os resultados do programa de revegetação foram avaliados, numa única campanha, mediante a aplicação de indicadores (ALMEIDA, 2002): (a) aspecto visual, (b) densidade de plantas, (c) altura média de plantas, (d) número de espécies arbóreas e (e) mortalidade de mudas. Para a delimitação da área de medições, utilizou-se o método de parcelas sugerido por Rodrigues (1989), e determinou-se uma distribuição aleatória restrita de parcelas. Assim, foram delimitadas parcelas de 30 × 12 m (6 parcelas na Mineração Viterbo e 5 na Mineração Cinco Lagos). Em cada parcela foram contabilizados o número de plantas-matriz (PM), referente às espécies arbóreas plantadas, e o número de plantas não-matriz (PNM), referente às espécies nativas emergentes provenientes da regeneração natural, e tomadas as respectivas medidas de altura. A porcentagem de mortalidade de PM foi calculada a partir do número de mudas que não vingaram em relação ao número total de mudas plantadas. Para analisar o aspecto visual, a pesquisa se valeu da observação in situ e elaboração de perfis-diagrama das áreas revegetadas.

Para a identificação das espécies arbóreas, coletaram-se amostras em campo, tanto das PM quanto das PNM, com o auxílio de "mateiros", conhecedores em profundidade das espécies vegetais locais. As amostras foram encaminhadas ao Departamento de Ecologia Vegetal do Instituto de Biociências da Universidade de São Paulo para efeito de identificação final.

Na escolha dos indicadores aplicáveis, a seleção daqueles a serem utilizados no estudo-piloto e na definição dos valores de referência que serão empregados na avaliação dos resultados dos programas de revegetação foi elaborada, conforme mostrado na Tabela 1, válida para o domínio de Mata Atlântica no Estado de São Paulo. A literatura fornece diversos exemplos de indicadores que podem ser empregados na avaliação dos resultados da recuperação de áreas degradadas. No entanto, vários desses indicadores demandam a coleta de dados extensivos ou sua aplicação necessita de conhecimentos científicos especializados. Tais características dificultam seu uso por empresas de pequeno ou médio porte, como a maioria das mineradoras de areia. Os valores de referência da Tabela 1 foram extraídos de fontes bibliográficas e das Resoluções SMA 42/96 e SMA 21/01. Naturalmente, eles devem ser adequados às condições específicas de cada localidade e levar em conta a dimensão temporal.

\section{RESULTADOS E DISCUSSÃO}

\subsection{Mineração Viterbo}

A Figura 1 proporciona uma idéia do aspecto visual da vegetação restabelecida. Observa-se, nessa figura, que na área com cinco anos o crescimento das mudas é pouco vigoroso, com plantas que variam de 0,7 a $5 \mathrm{~m}$. Não há estrato emergente, pois a manutenção impede o crescimento de qualquer outra espécie. Entretanto, a área com nove anos, sem nenhum tipo de manutenção, e, apesar de ter sido semeada só com gramíneas, apresenta uma regeneração natural vigorosa, com crescimento tanto de espécies arbóreas quanto de herbáceas. Constatou-se também a presença de clareiras (áreas sem espécies arbóreas), as quais coincidem com as partes da bacia onde o substrato é mais compacto e o crescimento de herbáceas, mais agressivo.

$\mathrm{Na}$ Tabela 2, apresentam-se os resultados de densidade e altura média de plantas. $\mathrm{Na}$ área com cinco anos, a densidade de 618 plantas/ha foi obtida somente das PM e, com certeza, seria maior se não fosse o tipo de manutenção praticado que impede o crescimento de PNM. O valor resultou muito baixo em relação ao de referência de 1.480 plantas/ha (Tabela 1). O mesmo aconteceu com a altura média obtida de 2,03 m, em comparação com o valor de referência de $3 \mathrm{~m}$ dessa mesma tabela. Esse parâmetro não reflete de maneira contundente a situação no campo, onde se observou que as espécies se dividiam em dois grupos: aquelas que tiveram muito desenvolvimento e as que praticamente não desenvolveram. Por exemplo, o jambolão (Syzygium jambos) é uma das poucas espécies que apresentou bom desenvolvimento e alturas acima de $4 \mathrm{~m}$, em relação a muitas outras espécies com alturas inferiores a $80 \mathrm{~cm}$. Na área revegetada com nove anos, a densidade de 2.000 plantas/ha é maior que o valor de referência da Tabela 1, considerando-se que todas são PNM provenientes da regeneração natural. Porém, a altura média de 2,51 m não atinge o valor de referência ( $3 \mathrm{~m})$ apresentado na Tabela 1 . 
A porcentagem de mortalidade das PM é apresentada na Tabela 3 . No caso de áreas revegetadas com cinco anos, a média obtida de $38 \%$ de mortalidade de mudas ficou muito acima do valor de $10 \%$ tido como valor de referência. Isso, provavelmente, reflete a pouca resistência de algumas espécies às condições do substrato característico das bacias de disposição de rejeitos, que apresentam alta compactação e baixo índice de porosidade. Como a área com nove anos não tem PM, o dado é inexistente.

O número de espécies arbóreas (Tabela 4) encon- tradas na área com cinco anos totalizou 20, em que 12 eram nativas e oito exóticas, comprovando que nem todas as mudas plantadas eram de espécies nativas. Das 12 espécies nativas, sete eram pioneiras e cinco não-pioneiras (Tabela 5). Na área com nove anos, encontraram-se 10 espécies nativas e duas exóticas. Nesse caso, provavelmente todas as árvores tiveram sua origem na propagação zoocórica ou anemocórica das sementes provenientes das áreas florestais circunvizinhas. Em nenhuma das áreas atingiu-se o valor de referência de 30 espécies por hectare.

Tabela 1 - Indicadores de desempenho aplicáveis na avaliação de áreas revegetadas em minerações de areia no Estado de São Paulo

Table 1 - Performance indicators for evaluating revegetation in sand mined areas (São Paulo State)

\begin{tabular}{|c|c|c|c|c|c|}
\hline Tipo de Indicador & Subtipo & $\begin{array}{c}\text { Indicador } \\
\text { (unidade de medida) }\end{array}$ & $\begin{array}{l}\text { Parâmetros para } \\
\text { Monitoramento }\end{array}$ & Aplicação & $\begin{array}{l}\text { Valores } \\
\text { de Referência* }\end{array}$ \\
\hline \multirow[t]{12}{*}{ Vegetação } & Implantação & $\begin{array}{c}\text { Mortalidade } \\
\text { de mudas }(\%)\end{array}$ & $\begin{array}{c}\mathrm{N}^{\circ} \text { de mudas mortas } \\
/ \mathrm{n}^{\circ} \text { total de } \\
\text { mudas plantadas }\end{array}$ & Todos & $10 \%$ \\
\hline & Pós-Implantação & $\operatorname{Biomassa}\left(\mathrm{m}^{3} / \mathrm{ha}\right)$ & $\mathrm{DAP}^{(8)}$, altura do fuste & Arbóreas & - \\
\hline & & Área basal $\left(\mathrm{m}^{2} / \mathrm{ha}\right)$ & Diâmetro na base do tronco & Arbóreas & - \\
\hline & & Altura média de planta (m) & Altura da planta & Arbóreas & $3 \mathrm{~m}^{(1)}$ \\
\hline & & Densidade (indivíduos/ha) & Número de indivíduos/área & Arbóreas & $1.480 \mathrm{ind} . / \mathrm{ha}^{(1)}$ \\
\hline & & Grau de sombreamento $\left(\mathrm{m}^{2} / \mathrm{ha}\right)$ & Projeção da copa & Arbóreas & $10.000 \mathrm{~m}^{2(1)}$ \\
\hline & & Serrapilheira (kg/ha/ano) & Acumulação de serrapilheira & Arbóreas & $9.400 \mathrm{~kg} / \mathrm{ha} / \mathrm{ano}^{(2)}$ \\
\hline & & Diversidade de espécies nativas & $\mathrm{N}^{\circ}$ espécies nativas & Matas ciliares & 30 espécies/ha ${ }^{(3)}$ \\
\hline & & Frequiência $(\%)$ & $\begin{array}{c}\text { Porcentagem de pioneiras } \\
\text { e climácicas }\end{array}$ & Arbóreas nativas & $\begin{array}{l}90 \% \text { pioneiras, } \\
10 \% \text { climácias }^{(1)}\end{array}$ \\
\hline & & $\begin{array}{l}\text { Índice de Valor de Importância } \\
\qquad \text { IVI }^{9}\end{array}$ & $\begin{array}{c}\text { Freqüuencia/densidade/ } \\
\text { cobertura }\end{array}$ & Arbóreas & - \\
\hline & & Presença de sub-bosque ${ }^{(9)}$ & Presença de plantas jovens & Arbóreas & Recomendável $^{(4)}$ \\
\hline & & Aspecto visual da vegetaçãao ${ }^{(9)}$ & $\begin{array}{l}\text { Presença de sub-bosque, } \\
\text { regeneração natural, tipo } \\
\text { de dossel, clareiras... }\end{array}$ & Todos & Recomendável $^{(4)}$ \\
\hline \multirow[t]{8}{*}{ Solo } & Físicos & Permeabilidade (cm/hora) & Taxa de infiltração de água & Todos & $>5 \mathrm{~cm} /$ hora $^{(5)}$ \\
\hline & & Compactação (g/cm3) & Densidade aparente & Todos & $1,2-1,3 \mathrm{~g} / \mathrm{cm}^{3(5)}$ \\
\hline & & Porosidade total $(\%)$ & Índice de vazios & Herbáceas em solos & $\quad>20 \%$ \\
\hline & & Perfil de enraizamento $(\mathrm{cm})$ & Comprimento de raízes & Solos & $150 \mathrm{~cm}^{(5)}$ \\
\hline & & Erosão laminar (t/ha/ano) & Perda de solo & Plantios jovens & 6 t/ha/ano ${ }^{(5)}$ \\
\hline & Físicos-Químicos & CTC (meg/100 g de solo) & $\begin{array}{l}\text { Cátions absorvidos na } \\
\text { solução solo }\end{array}$ & Todos & $>20^{(6)}$ \\
\hline & & Carbono orgânico (\%) & Matéria orgânica do solo & Todos & $5-10 \%(5)$ \\
\hline & & $\mathrm{pH}^{(9)}$ & $\mathrm{pH}$ & Todos & $5,5-6,5^{(6)}$ \\
\hline Bioindicador & Fauna do solo & Diversidade de formigas & Número de espécies & Arbóreas nativas & $>20$ espécies $^{(7)}$ \\
\hline
\end{tabular}

* Valores propostos em referências bibliográficas significando que:

(1) Critério legal para o Vale do Paraíba, (Res. SMA 42/96)

(2) Valor médio para floresta estacional secundária. Meguro et al (1979)

(3) Critério legal para matas ciliares, (Res. SMA 21/01)

(4) Rodrigues e Gandolfi (1998)

(5) Lal (1999)

6) Gonçalves e Poggianni (1996)

(7) Fowler (1998)

(8) Diâmetro à altura do peito

(9)Adimensional

(a) com estes valores o crescimento de vegetação não está comprometido e, (b) os valores considerados devem ser adequados às condições. 

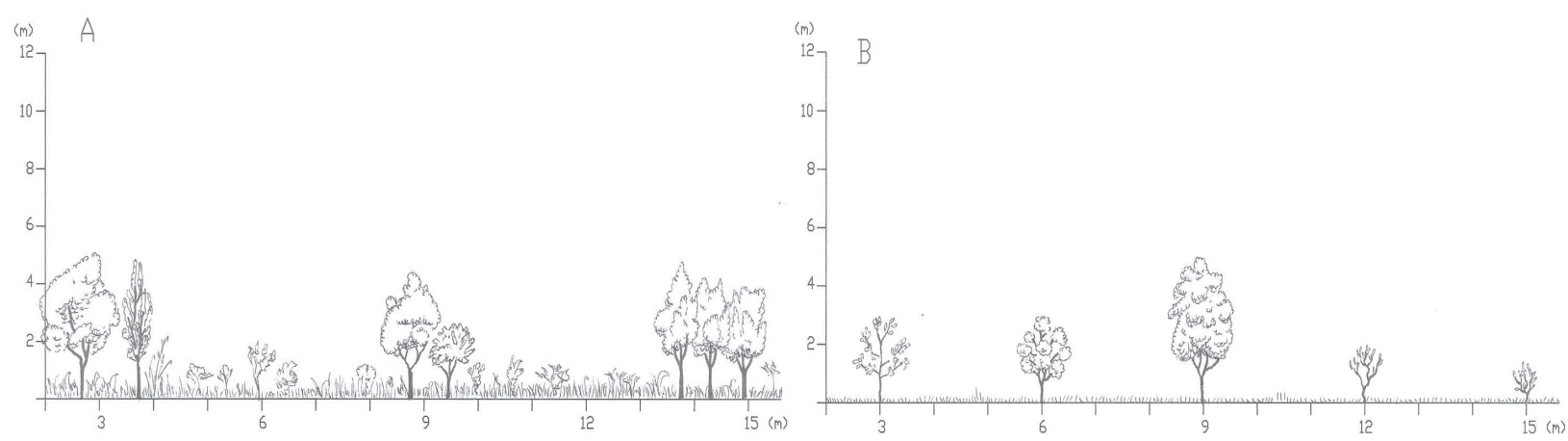

Figura 1 - Perfis-diagrama das revegetações com nove anos (perfil A) e com cinco anos (perfil B) da Mineração Viterbo. Figure 1 -Schematic profile of nine year revegetation (profile A) and five year revegetation (profile B), in Viterbo Mine.

Tabela 2 - Densidade e altura média(m) das plantas-matriz (PM) e plantas não -matriz (PNM), nas áreas avaliadas Table 2-Average density and height average of established and emergent plants

\begin{tabular}{|c|c|c|c|c|c|c|c|c|}
\hline Mineração & Idade & Espaçamento & $\begin{array}{l}\mathrm{PM} / \mathrm{ha} \\
(\mathrm{mxm})\end{array}$ & $\mathrm{PNM} / \mathrm{ha}$ & $\begin{array}{c}\text { Total de } \\
\text { Plantas/ha }\end{array}$ & $\begin{array}{c}\text { Altura } \\
\text { Média PM }\end{array}$ & $\begin{array}{c}\text { Altura } \\
\text { Média PNM }\end{array}$ & $\begin{array}{c}\text { Altura } \\
\text { Média Geral }\end{array}$ \\
\hline \multirow[t]{2}{*}{ Viterbo } & 5 anos & $3 \times 3$ & 618 & $\longrightarrow$ & 618 & 2,03 & - & 2,03 \\
\hline & 9 anos & $\mathrm{RN}^{(1)}$ & $\longrightarrow$ & 2.000 & 2.000 & - & 2,51 & 2,51 \\
\hline Cinco & 7 anos & $6 \times 1$ & 1.069 & 1.111 & 2.181 & 7,63 & 2,47 & 5,05 \\
\hline Lagos & 7 anos & $3,5 \times 2,5$ & 1.297 & 481 & 1.778 & 6,80 & 3,78 & 5,29 \\
\hline
\end{tabular}

(1) RN: regeneracão natural

Tabela 3 - Porcentagem de mortalidade de plantas-matriz (PM) nas áreas avaliadas

Table 3 -Mortality of established plants in revegetated areas

\begin{tabular}{|c|c|c|c|}
\hline Mineração & $\begin{array}{l}\text { o } \text { Idade da } \\
\text { revegetação }\end{array}$ & Parcela & $\begin{array}{c}\text { Mortalidade } \\
(\%)\end{array}$ \\
\hline \multirow[t]{7}{*}{ Viterbo } & 9 anos & 1 & - \\
\hline & & 2 & $\longrightarrow$ \\
\hline & 5 anos & 3 & 52,5 \\
\hline & & 4 & 25 \\
\hline & & 5 & 24 \\
\hline & & 6 & 49 \\
\hline & Média & & 38 \\
\hline$\overline{\text { Cinco }}$ & Espaçamento & Parcela & Mortalidade \\
\hline Lagos & $(\mathrm{mxm})$ & & $(\%)$ \\
\hline \multirow[t]{3}{*}{ Área A } & $6 \times 1$ & 1 & 9,76 \\
\hline & & 2 & 6,1 \\
\hline & Média & & 7,93 \\
\hline \multirow[t]{4}{*}{ Área B } & $3,5 \times 2,5$ & 3 & 0 \\
\hline & & 4 & 2,17 \\
\hline & & 5 & 9,3 \\
\hline & Média & & 3,82 \\
\hline
\end{tabular}

\subsection{Mineração Cinco Lagos}

A Figura 2 proporciona uma idéia do aspecto visual da vegetação, observando-se que na área A (6 x $1 \mathrm{~m})$ o crescimento das plantas é vigoroso, com plantas que variam de 2 a $12 \mathrm{~m}$ de altura. As fileiras plantadas encontravam-se fechadas pelo crescimento lateral das árvores. No amplo espaço entre leiras (6 m), constatou-se a presença numerosa de plantas emergentes (PNM). Na área B (3,5 x 2,5 m), o crescimento lateral das árvores não chegou a fechar as fileiras, observando-se maior presença de espécies herbáceas e seus tamanhos variando de 2 a $12 \mathrm{~m}$ de altura.

Em ambos os distanciamentos, tanto a densidade quanto a altura média de plantas (Tabela 2) indicaram bons resultados, e a área $\mathrm{A}$ apresentou maior densidade (2.181 plantas/ha) que a área B (1.778 plantas/ ha), devido ao maior adensamento das PM. Como se pode observar na Tabela 2, tal fato se deveu também à maior quantidade de PNM registrada na área A. A mortalidade de PM (Tabela 3) dos dois distanciamentos foi menor que o valor de $10 \%$ de referência apontado na Tabela 1. 
Tabela 4 - Número de espécies nativas e exóticas arbóreas nas áreas avaliadas Table 4-Number of native and exotic tree species in revegetated areas

\begin{tabular}{lccccc}
\hline & Viterbo & & \multicolumn{2}{c}{ Cinco Lagos } \\
\hline Espécies & Exóticas & Nativas & Total & Exóticas & Nativas \\
Identificadas & 9 & 21 & 30 & 3 & 26 \\
Plantadas (PM) & 8 & 12 & 20 & 3 & 29 \\
Emergentes (PNM) & 2 & $10^{(1)}$ & 12 & 1 & 13 \\
\hline
\end{tabular}

(1) Nove destas espécies são diferentes das espécies plantadas.

(2) Treze destas espécies são diferentes das espécies plantadas.

Tabela 5 - Número de espécies pioneiras e não-pioneiras nas áreas avaliadas Table 5 - Number of pioneer and non pioneer species in revegetated areas

\begin{tabular}{|c|c|c|c|c|c|c|}
\hline & Viterbo & & & & Cinco Lagos & \\
\hline Espécies & Nativas & Pioneiras & Não Pioneiras & Nativas & Pioneiras & Não Pioneiras \\
\hline Identificadas & 21 & 14 & 7 & 26 & 15 & 11 \\
\hline Plantadas (PM) & 12 & 7 & 5 & 13 & 9 & 4 \\
\hline Emergentes (PNM) & 10 & 8 & 2 & 16 & 8 & 7 \\
\hline
\end{tabular}
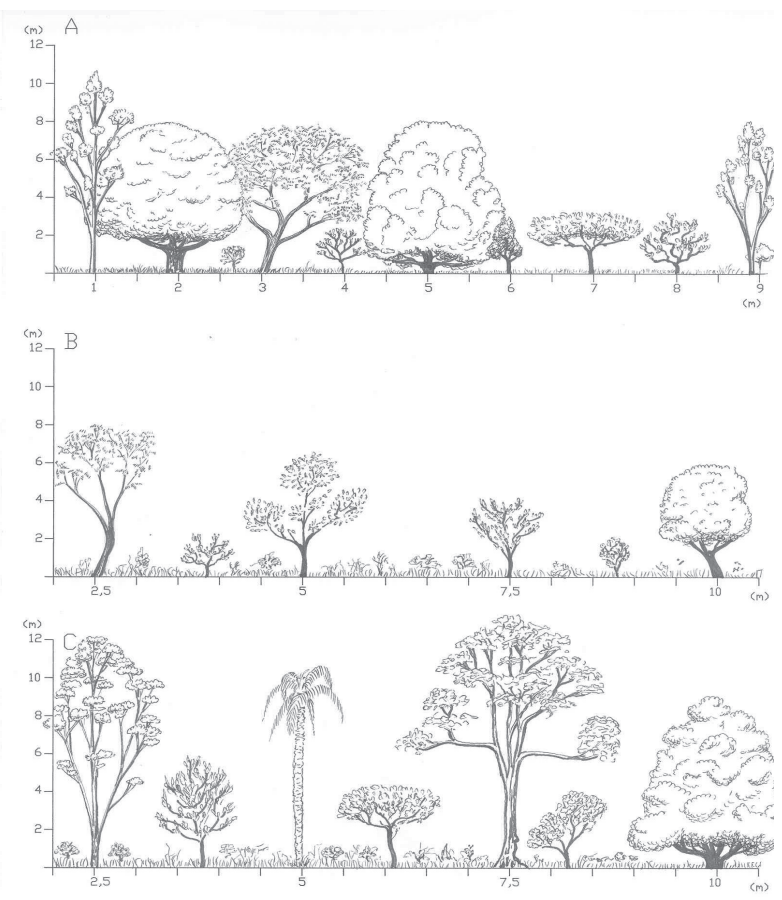

Figura 2 - Perfis-diagrama da revegetação com espaçamentos: $6 \times 1 \mathrm{~m}$ (perfil A); 3,5 x 2,5 m (perfil B); e 3,5 x 2,5 m (perfil C) na Mineração Cinco Lagos. O perfil C corresponde a uma área localizada próxima a um fragmento remanescente de vegetação nativa.

Figure 2 - Profile of a revegetated area in Cinco Lagos pit featuring the following distances between lines and rows: $6 x 1 m$ (profile A), 3,5mx2,5m (profile $B$ ) and 3,5mx2,5m (profile C).
Os bons resultados obtidos desses indicadores podem estar relacionados à prática de plantio em leiras, o que favoreceu as condições de drenagem no terreno (com risco de inundação na época das chuvas). A área A $(6 \times 1 \mathrm{~m})$ pode ter permitido melhores condições para o crescimento da vegetação, devido à maior facilidade para manutenção mecanizada durante os primeiros anos de plantio. Posteriormente, o intenso crescimento de PNM pode ter sido facilitado pelas boas condições de drenagem e pela produção de sombra das PM já mais desenvolvidas. O número de espécies nativas e exóticas identificadas na Tabela 4 refere-se às duas áreas, já que a diversidade de mudas plantadas foi a mesma, só tendo variado o distanciamento. Foram identificadas 29 espécies arbóreas, 26 nativas e três exóticas. A Tabela 1 indica que as áreas deveriam ter, pelo menos, 30 espécies nativas diferentes por hectare, tratando-se da revegetação de uma mata ciliar. As espécies emergentes correspondem a 16 nativas e uma exótica, o que reflete as boas condições de regeneração natural. Das 26 espécies nativas, 15 são pioneiras e 11, nãopioneiras (Tabela 5).

\section{CONCLUSÕES}

A revegetação nas áreas estudadas vem cumprindo o propósito de manter a estabilidade física. Porém, com base nos parâmetros estabelecidos pela Resolução SMA 42/96 para implantação de vegetação nativa, tidos como valores de referência, conclui-se que as áreas avaliadas ainda não estão revegetadas satisfatoria- 
mente, pois os valores de referência estipulados não foram todos atingidos. As espécies plantadas não são apenas nativas, e seu número é insuficiente. Em ambos os casos avaliados, constatou-se que a regeneração natural estava sendo um fator determinante na diversificação de espécies.

Os indicadores utilizados revelaram-se eficazes para a avaliação pretendida, uma vez que podem ser aplicados com procedimentos de baixo custo, demandam pouco tempo, não exigem conhecimento especializado e caracterizam satisfatoriamente o estado da área revegetada. Tais indicadores podem contribuir para a tomada de decisões futuras, nestes e em casos similares, por exemplo, na consideração de uma área como "oficialmente" recuperada, seja para fins de quitação de compromissos assumidos por via contratual (com o proprietário do terreno), administrativos (com um ou mais órgãos públicos) ou judiciais. Em jurisdições onde é exigida uma caução ou garantia financeira para recuperação ambiental, atingir o nível de referência pré-estipulado para um conjunto de indicadores seria condição para resgate ou devolução do montante financeiro apresentado em garantia.

\section{REFERÊNCIAS BIBLIOGRÁFICAS}

ALMEIDA, R.O.P.O. Revegetação de áreas mineradas: estudo dos procedimentos aplicados em minerações de areia. 2002, 160f. Dissertação (Mestrado em Engenharia Mineral) - Escola Politécnica da Universidade de São Paulo, São Paulo, 2002.

BITAR, Y. O. Avaliação da recuperação de áreas degradadas por mineração na região metropolitana de São Paulo. 1997, 184f. Tese (Doutorado em Engenharia Mineral) - Escola Politécnica da Universidade de São Paulo. São Paulo.

DIAS, E.G.C.S.; SÁNCHEZ, L.E. Deficiências na implementação de projetos submetidos à avaliação de impacto ambiental no Estado de São Paulo. Revista de Direito Ambiental, n.23, p.163-204, 2001

DEPARTAMENTO NACIONAL DA PRODUÇÃO MINERAL - DNPM. Sumário mineral 2002. Brasília.

FOWLER, H. Provas de melhoria ambiental. Ciência Hoje, v. 24, n.142, p. 69-71, 1998.
GONÇALVES, J.; POGGIANNI, F. Substratos para produção de mudas florestais. In: CONGRESSO LATINO AMERICANO DE CIÊNCIA DO SOLO, 13., 1996. Águas de Lindóia. Anais... Águas de Lindóia, Universidade de São Paulo, 1996. CDROM

LAL, R. Métodos para avaliação do uso sustentável dos recursos solo e água nos trópicos. Jaguariúna: Embrapa Meio Ambiente, 1999.97p.

MEGURO, M.; VINNEZA, G.; DELITTI, W.

Ciclagem de nutrientes minerais na Mata Mesófila Secundária - São Paulo. I. Produção e conteúdo de nutrientes minerais na serapilheira. Boletim de Botânica da Universidade de São Paulo, v.7, p.11-31, 1979.

RODRIGUES, R. Análise estrutural das formações florestais ripárias. In: BARBOSA, L. (Coord.). Simpósio sobre matas ciliares. MogiGuaçú: 1989.p. 99-116.

RODRIGUES, R.; GANDOLFI, S. Restauração de florestas tropicais: subsídios para uma definição metodológica e indicadores de avaliação e monitoramento. In: DIAS, L.; MELLO, J. (Eds.) Recuperação de áreas degradadas. Viçosa: Universidade Federal de Viçosa/ SOBRADE, 1998. p. 203-215.

RODRIGUES, R.; GANDOLFI, S. Conceitos tendências e ações para a recuperação de florestas ciliares. In: RODRIGUES, R. R.; LEITÃO FILHO, H.R.(Eds.). Matas ciliares: conservação e recuperação. 2 ed. São Paulo, Edusp, 2001. p. 235-247.

SANTO, E.; SÁNCHEZ, L.E. GIS applied to determine environmental impact indicators made by sand mining in a floodplain in southeastern, Brazil. Environmental Geology, v. 41, p.628-637, 2002.

SWAINE, M.D.; WHITMORE, T.C. On the definition of ecological species groups in tropical rain forests. Vegetatio, 75:81-86, 1988.

WEST, D.C.; SHUGART, H.H.; BOTKIN, D.B. (Eds.) Forest succession: concepts and applications. New York: Springler-Verlag, 1981. $517 \mathrm{p}$. 